\title{
A silicon photonic design concept for a chip-to-fibre orbital angular momentum mode- division multiplexer
}

Baumann, Jan Markus; Ingerslev, Kasper; Ding, Yunhong; Frandsen, Lars Hagedorn; Oxenløwe, Leif Katsuo; Morioka, Toshio

\section{Published in:}

The European Conference on Lasers and Electro-Optics 2019

Link to article, DOI:

10.1109/cleoe-eqec.2019.8872253

Publication date:

2019

Document Version

Peer reviewed version

Link back to DTU Orbit

Citation (APA):

Baumann, J. M., Ingerslev, K., Ding, Y., Frandsen, L. H., Oxenløwe, L. K., \& Morioka, T. (2019). A silicon photonic design concept for a chip-to-fibre orbital angular momentum mode-division multiplexer. In The European Conference on Lasers and Electro-Optics 2019 [Paper pd_1_9] IEEE. https://doi.org/10.1109/cleoeeqec.2019.8872253

\section{General rights}

Copyright and moral rights for the publications made accessible in the public portal are retained by the authors and/or other copyright owners and it is a condition of accessing publications that users recognise and abide by the legal requirements associated with these rights.

- Users may download and print one copy of any publication from the public portal for the purpose of private study or research.

- You may not further distribute the material or use it for any profit-making activity or commercial gain

- You may freely distribute the URL identifying the publication in the public portal 


\title{
A silicon photonic design concept for a chip-to-fibre orbital angular momentum mode-division multiplexer
}

\author{
Jan Markus Baumann ${ }^{1}$, Kasper Ingerslev ${ }^{1}$, Yunhong Ding ${ }^{1}$, Lars Hagedorn Frandsen ${ }^{1}$, Leif Katsuo \\ Oxenløwe ${ }^{1}$, Toshio Morioka ${ }^{1}$ \\ 1. DTU Fotonik, Department of Photonics Engineering, Technical University of Denmark, DK-2800, Lyngby, Denmark
}

Orbital angular momentum (OAM) modes in fibres are modes that potentially can be used for mode-division multiplexing systems. OAM modes possess a helical phase front which can be written as $\exp (i \mathrm{~L} \varphi)$, with $\mathrm{L}$ being the topological charge and $\varphi$ being the azimuthal coordinate. Here, we present a chip capable of multiplexing waveguide modes to OAM modes in a fibre in the C-band.
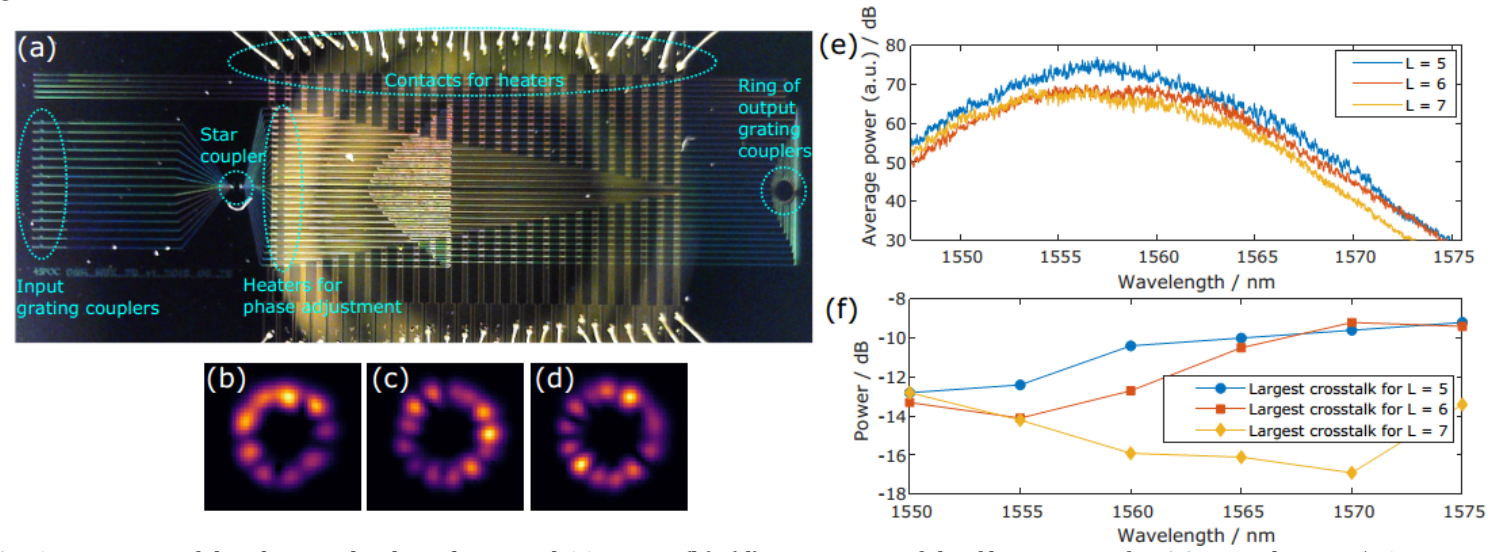

Fig. 1 (a) Image of the chip, with a length around $11.7 \mathrm{~mm}$. (b)-(d): IR images of the fibre output for OAM modes $\mathrm{L}=5,6$ and 7. (e) Measured output power of the fibre. The spectral shape stems mainly from the bandwidth of the grating couplers. (f) Power of the mode with provides the largest crosstalk component measured using the $S^{2}$ method in relation to the desired mode. In most cases, the largest crosstalk came from the neighbouring OAM modes $(|\Delta \mathrm{L}|=1)$.

Figure 1(a) shows the designed chip which is fabricated on a silicon-on-insulator platform. It consists of 15 input grating couplers for a possible multiplexing to OAM modes with $\mathrm{L}$ ranging from -7 to +7 . A star coupler is utilized to split the incoming signal and create the needed phase differences of multiples of $\Delta \varphi=2 \pi \mathrm{L} / 26$ to each of the 26 output ports, which are connected to a ring of 26 grating couplers all oriented the same direction and are used to output the signal to a fibre. The waveguides between the star coupler and the output grating couplers are matched in length to preserve the phase differences over a large bandwidth. A heating element is put above each waveguide to fine-tune the phases, if required.

To couple from the chip to the OAM fibre, the on-chip coupler ring is imaged onto the fibre facet at an appropriate scaling ration using two lenses. Furthermore, a quarter-wave plate is inserted into the beam path to convert the linear polarization of light emitted by the chip to the circular polarization of the OAM modes inside the fibre. For the characterization of the chip, a short, $\sim 2 \mathrm{~m}$ long OAM fibre was used. The fibre consists of a step-index core with an air-hole in the middle and is designed to support OAM modes with $\mathrm{L}=+/-5,6$ and 7 [1]. At the output of the fibre, the beam is collimated and imaged with an infrared (IR) camera (see Figs. 1(b)(d)). The output beam can be sent to a spatial light modulator (SLM) after converting it to linear polarization with a quarter-wave plate to analyse the mode content of the beam. To set the on-chip heaters, the wanted mode is transformed to a Gaussian-like field with $\mathrm{L}=0$ by the SLM by putting on the inverse OAM phase pattern. In a feedback loop, the heater voltages are optimized to maximise the power in the targeted mode. In this experiment, the system and heaters were optimized for $\mathrm{L}=7$ at $1560 \mathrm{~nm}$.

To analyse the mode content in the fibre, the spatial and spectral $\left(\mathrm{S}^{2}\right)$ imaging method like in [2] is used, by imaging the output while sweeping the wavelength of the input laser. The power of the largest crosstalk component is shown in Fig. 1(f). The mode which provides the largest crosstalk is typically around 10-15 $\mathrm{dB}$ below the desired mode. For $\mathrm{L}=5$ at $1560 \mathrm{~nm}$, the total power loss of the whole system is $\sim 36 \mathrm{~dB}$, of which $\sim 16-17 \mathrm{~dB}$ comes from the chip.

The coupling to OAM modes with $\mathrm{L}=5,6$ and 7 is successfully demonstrated within the C-band. The modes with $L=-5,-6$ and -7 were not used in this experiment due to minor fabrication errors, but should be possible to use in future improved versions of this device.

\section{References}

[1] P. Gregg, P. Kristensen, and S. Ramachandran, “Conservation of orbital angular momentum in air-core optical fibers,” Optica, 2, 267 (2015).

[2] J. W. Nicholson, A. D. Yablon, J. M. Fini, and M. D. Mermelstein, “Measuring the modal content of large-mode-area fibers,” IEEE J. Sel. Top. Quantum Electron., vol. 15, no. 1, pp. 61-70, 2009. 